\title{
State of the art of solid freeform fabrication for soft and hard tissue engineering
}

\author{
P. J. S. Bártolo \\ Department of Mechanical Engineering and Institute for Polymers and \\ Composites, School of Technology and Management, \\ Leiria Polytechnic Institute, Portugal
}

\begin{abstract}
Tissue engineering is an interdisciplinary field involving the combined efforts of cell biologists, engineers, material scientists, mathematicians and geneticists towards the development of biological substitutes to restore, maintain, or improve tissue functions. It has emerged as a rapidly expanding field to address the organ shortage problem.

Advanced solid freeform fabrication techniques are now being developed to fabricate scaffolds with controlled architecture for tissue engineering. These techniques combine computer-aided design (CAD) with computer-aided manufacturing (CAM) tools to produce three-dimensional structures layer-by-layer in a multitude of materials.

This paper introduces the concept of tissue engineering assisted by computer. Different solid freeform fabrication techniques for tissue engineering are described and their advantages and disadvantages discussed with great detail. Novel fabrication procedures, such as alginate rapid prototyping and cell printing, are also presented opening new and exciting possibilities within the tissue engineering field.
\end{abstract}

\section{Introduction}

In 1988, the concept of tissue engineering was presented for the first time as "the application of the principles and methods of engineering and life sciences toward fundamental understanding of structure-function relationship in normal and mammalian tissues and the development of biological substitutes for the repair or regeneration of tissues or organ functions" [1]. In 2003, 87717 patients were 
waiting for organ transplantation in USA alone [2]. This number has increased to 88598 by May 2005, while 4375 transplants were performed between January and February 2005[3]. Although clinics have tried to replace the function of failing organs mechanically or through implantation of synthetic replacements, these are often only temporary solutions, not allowing the patient to completely resume normal activities. Moreover, infection and device rejection are also serious concerns in such procedures.

Tissue engineering has emerged to address the organ shortage problem as cells might be able to organise into tissue and organ replacements when cultured in 3D under proper reactor conditions [4]. Scaffolds have been produced from either natural or synthetic materials to create the $3 \mathrm{D}$ environment for cellular attachment, migration, proliferation and differentiation [5]. These scaffolds must degrade slowly after implantation in a patient, being replaced by new tissue [6], so playing an important role as delivery vehicles for the sustained release of tissue growth factors, promoting natural wound healing and regeneration [7-8].

Several techniques were developed to produce $3 \mathrm{D}$ scaffolds for tissue engineering. The conventional techniques include fibre bonding, solvent casting, particulate leaching, membrane lamination, microwave baking and expansion, high pressure based methods and melt based technologies [9-12]. However, these techniques do not properly control pore size, pore geometry and spatial distribution of pores, besides being very difficult to construct internal channels within the scaffold. Beyond these limitations, these techniques involve the use of toxic organic solvents, long fabrication times on top of being labour-intensive processes.

Solid freeform fabrication (SFF) represents a new group of nonconventional techniques were recently introduced in the medical field. The main advantages of SFF are both the capacity to rapidly produce very complex 3D models and the ability to use various raw materials and surface finishing processes. In the medical field, SFF models have been mainly used for assisting diagnosis, planning treatment and manufacturing implants particularly in oral and maxillofacial surgery. Recently, SFF have been explored to produce scaffolds with customised external shape and predefined internal morphology $[2,13]$. In this case, SFF also allows one to control pore size and pore distribution $[2,9]$.

Figure 1 provides a general overview of the necessary steps to produce SFF scaffolds for tissue engineering. The first step to produce a 3D scaffold through rapid prototyping is the generation of the corresponding computer solid model through one of the currently available techniques. These imaging methods produce continuous volumetric data (voxel-based data), which provide the input data for model generation. The model is then tessellated as an STL file, which is currently the standard file for facetted models. Finally, the STL model is mathematically sliced into thin layers (sliced model). The SFF systems use the slice data to replicate a physical object layer-by-layer.

Data acquisition techniques available for medical imaging and different SFF processes and its applications in the field of tissue engineering are described in the following sections of this paper. 


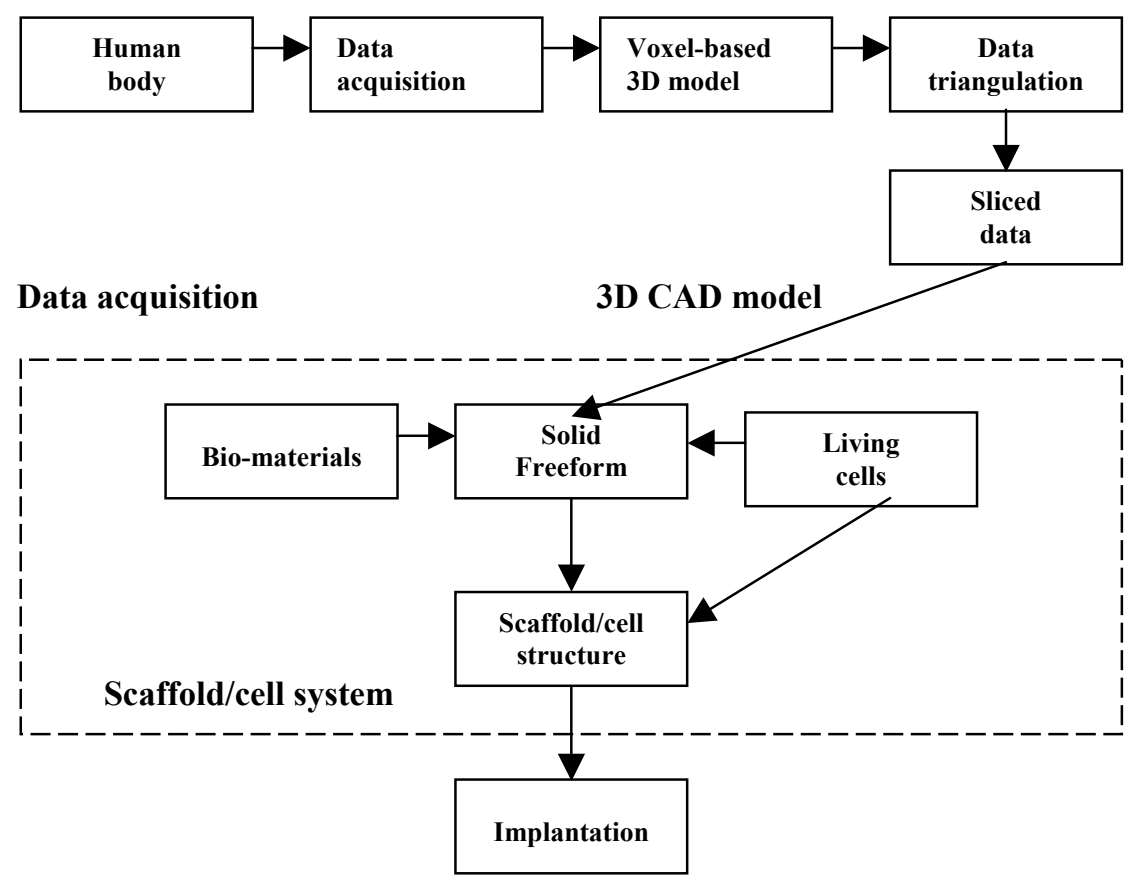

Figure 1: $\quad$ Steps for rapid prototyping scaffolds.

\section{Data acquisition}

Since the discovery of X-rays by Röentgen in 1895, medical imaging has made remarkable progress, playing a central role in medical care. The primary data acquisition techniques used in tissue engineering are:

- Computer tomography (CT) introduced in early 1970s as a neurological examination technique. It requires the exposure of a sample to small X-ray quantities, the absorption of which is detected and imaged. The result is a series of $2 \mathrm{D}$ images displaying a density map of the sample. The image contrast represents differences in X-ray attenuation. Stacking the images together create a $3 \mathrm{D}$ representation of the scanned data. Diverse software tools have been developed for 3D representation of $\mathrm{CT}$ data, like Velocity2 Plus (Javelin, USA), BioBuild (Anatomics, Australia), MIMICS (Materialise, Belgium) and InVesalius (CenPRA, Brazil) [14-17]. Recent developments comprise multislice $\mathrm{CT}$, which uses multistage detectors for simultaneous collection of multislice data, as well a cone-beam CT using a flat panel detector providing highly precise 3D data $[18,19]$.

- Magnetic resonance imaging (MRI) based on the magnetisation of water molecules, present in different concentrations for most types of tissues. MRI is more expensive and complex than $\mathrm{CT}$, though it has an extensive application, due to its non-invasive and non-radiative nature [18]. An important disadvantage is the time a patient is required to be motionless during scanning. 
Key current topics of research include both the improvement of image quality for fast imaging and the accuracy of functional MRI, as well the development of ultra-high magnetic field devices.

- Nuclear medical imaging (NMI) or molecular imaging is a process in which a radiochemical compound is injected and the information is obtained by both its distribution inside the body and density changes over time. In NMI, the main methods are single-photon emission CT (SPECT) using $\gamma$-emitting nuclei and positron emission tomography (PET), and positron-emitting nuclei.

- 3D ultrasound is a promising medical imaging technique performed through modern scanners that are inexpensive, portable and safe [20]. Many different acquisition approaches have been developed for 3D ultrasound imaging. These approaches comprise 2D transducers arrays, mechanical scanners, and freehand methods [20]. Many features of modern scanners intend to improve both the overall usability of the devices and the automatic image optimisation. Important developments are expected for ultrasound imaging areas like mechanical properties of tissues, molecular imaging and gene therapy.

X-ray imaging is widely used to acquire morphological information, while magnetic resonance imaging is used to acquire both morphological and functional information [19]. Ultrasound imaging is better suited for acquiring functional information and nuclear medical imaging is used to obtain information on metabolism and molecular behaviour [19].

\section{SFF in tissue engineering}

The most important SFF processes for tissue engineering are:

- Photo-polymerisation or stereolithographic processes: use an ultraviolet (UV) laser beam to selectively solidify successive thin layers of photo-sensitive polymers, each built on top of the previous layer. The laser beam is guided onto the polymer surface in accordance to cross-sectional data. Support structures are required.

Levy et al. [21] used a direct irradiation stereolithographic process to produce hydroxyapatite (HA) ceramic scaffolds for orbital floor prosthesis. A suspension of fine HA powder into a UV-photocurable resin was formulated and used as building material. The photo-cured resin acts as a binder to hold the HA particles together. The resin is then burnt out and the HA powder assembly sintered for consolidation. A similar approach was used by Griffith and Halloran [22] that produced ceramic scaffolds using suspensions of alumina, silicon nitride and silica particles with a photo-curable resin. The binder was removed by pyrolysis and the ceramic structures sintered. Matsuda and Mizutani [23] developed a biodegradable, photocurable copolymer, acrylate-endcapped poly( $\varepsilon$-caprolactone-co-trimethylene carbonate) to produce scaffolds through stereolithographic processes. Very promising is also the research conducted by microTEC on the rapid micro product development (RMPD) concept [24]. 
- Laser sintering processes: uses a high-power carbon dioxide laser emitting infrared radiation, to selectively heat powder material just beyond its melting point. The laser traces the shape of each cross-section of the model to be built, sintering powder in a thin layer. It also supplies energy that not only fuses neighbouring powder particles, but also bonds each new layer to those previously sintered. The sintering process takes place in a sealed heated chamber at a temperature near the powder melting point filled with nitrogen. Maintaining the hot environment in the build chamber also reduces both the power required from the laser and the thermal shrinkage of the model. After each layer is solidified, the piston over the model retracts to a new position and a new layer of powder is supplied using a mechanical roller. The powder that remains unaffected by the laser acts as a natural support for the model and remains in place until the model is complete.

Williams et al. [25] used selective laser sintering to produce porous PLC scaffolds, which were then seeded with bone morphogenetic protein-7 (BMP7) transduced fibroblasts. In vivo results show that these scaffolds enhance tissue in-growth, on top of possessing mechanical properties within the lower range of trabecular bone. Lee et al [26] coated calcium phosphate powder with polymer by spray drying slurry of particulate and emulsion binder. The coated powder was then sintered to fabricate calcium phosphate bone implants. Afterwards, these structures were infiltrated with calcium phosphate solution or phosphoric acid-based inorganic cement.

-

Extrusion processes: uses filaments of material that are melted by heating and guided by a robotic device (extruder), controlled by a computer, to form the $3 \mathrm{D}$ object. The material leaves the extruder in a liquid form and hardens immediately. The previously formed layer, which is the substrate for the next layer, must be maintained at a temperature just below the solidification point to assure good interlayer adhesion.

Wang et al. [27] used a novel precision extruding deposition (PED) process to directly fabricate cellular poly- $\varepsilon$-caprolactone (PCL) with controlled pore size of $250 \mu \mathrm{m}$ and designed structural orientations $\left(0^{\circ} / 90^{\circ}, 0^{\circ} / 120^{\circ}\right.$ or combined $0^{\circ} / 120^{\circ}$ and $0^{\circ} / 90^{\circ}$ patterns). Proliferation studies were performed using cardiomyoblasts, fibroblasts and smooth muscle cells. Additionally, mechanical tests were performed with the produced scaffolds showing compression modulus in the range between $150 \mathrm{MPa}$ and $200 \mathrm{MPa}$. Hutmacher et al. [28] optimised the extrusion processing parameters for the production of PCL honeycomb-like scaffolds. Similar work was conducted by Zein et al. [29] that produced PCL scaffolds with a range of channel size 160$700 \mu \mathrm{m}$, filament diameter $260-370 \mu \mathrm{m}$, porosity $48-77 \%$ and regular honeycomb pores. The compressive stiffness ranged from 4 to $77 \mathrm{MPa}$, yield strength from 0.4 to $3.6 \mathrm{MPa}$, and yield strain from $4 \%$ to $28 \%$. Other research studies carried out by Woodfield et al. [30], Chen et al. [31] and Widmer et al. [32] showed that extrusion processes can be used for tissue engineering.

-

Ink-jet printing: involves the bonding and the build up method. The bonding method deposits a stream of microparticles of a binder material over the surface of a powder bed, joining particles together to form the object. A 
piston lowers the powder bed so that a new layer of powder can be spread over the surface of the previous layer and then selectively joined to it. The build-up method emits a stream of microparticles just above their solidification temperature until an exact co-ordinate where they solidify. The jet heads build the product from bottom up, spraying one layer at a time.

Kim et al. [33] employed this SFF technique with particulate leaching to create porous scaffolds, using polylactide-coglycolide (PLGA) powder mixed with salt particles and a suitable organic solvent. The salt particles were leached using distilled water. Cylindrical scaffolds were fabricated measuring $8 \mathrm{~mm}$ (diameter) by $7 \mathrm{~mm}$ (height) with pore sizes of $45-150 \mu \mathrm{m}$ and $60 \%$ porosity. Hepatocytes were also successful attached to the scaffolds.

The influence of pore size and porosity on cell adhesion and proliferation were investigated by Zeltinger et al. [34]. Disc shaped poly(L-lactic acid) (LPLA) scaffolds measuring $10 \mathrm{~mm}$ (diameter) by $2 \mathrm{~mm}$ (height) were produced through both ink-jet printing and salt and leaching methods. The scaffolds were produced with two different porosities (75\% and 90\%) and four different pore size distributions $(<38,38-63,63-106$ and 106-150 $\mu \mathrm{m})$, and tested with cell culture using canine dermal fibroblasts, vascular smooth muscle cells and microvascular epithelial cells. The cell culture results produced show the suitability of ink-jet printing to fabricate scaffolds for tissue engineering. Lam et al. [35] developed a blend of starch-based powder containing cornstarch $(50 \%)$, dextran $(30 \%)$ and gelatine $(20 \%)$ that can be bound by printing distilled water. Cylindrical scaffolds were produced measuring $12.5 \mathrm{~mm}$ (diameter) by $12.5 \mathrm{~mm}$ (height) and infiltrated with different amounts of a copolymer solution consisting of $75 \%$ L-PLA and $25 \%$ polycaprolactone in dichloromethane to improve their mechanical properties. Sachlos et al. [36] uses an indirect approach to produce collagen scaffolds with complex internal morphology and macroscopic shape by using an ink-jet printing sacrificial mould. A dispersion of collagen was cast into the mould and frozen. The mould was then dissolved with ethanol and the collagen scaffold was critical point dried with liquid carbon dioxide. Other research works, like the ones of Taboas et al. [37], Limpanuphap and Derby [38] and Park et al. [39], have also exploited the capabilities of ink-jet printing for tissue engineering.

- Bio-plotting: is a novel dispersing technique developed at the Freiburg Materials Research Center, Germany, for soft tissue applications. The key feature of this process is the $3 \mathrm{D}$ dispersing of a viscous plotting material into a liquid medium with a matching density [40]. As a result of this buoyancy compensation, structures can be produced mostly without temporary support structures. A very large variety of materials can be processes including melts, pastes, reactive resins or hydrogels.

Ang et al. [41] developed a rapid prototyping robotic dispersing (RPBOD) using the same principle as the $3 \mathrm{D}$ bio-plotting system, which was used to produce chitosan-HA scaffolds. Solutions of chitosan-HA were extruded into a sodium hydroxide and ethanol medium to induce the precipitation of chitosan. The scaffolds were then hydrated, frozen and freeze-dried. 
A similar process, called alginate-based rapid prototyping, has been developed at the Polytechnic Institute of Leiria. This process produces alginate solid structures (Figures 2 and 3), by extruding a previously prepared solution of sodium alginate in water, mixed with a solution of calcium chloride, providing a temporary support for the seeded cells in culture. Alginate is one of the most versatile biopolymers, with a wide range of pharmaceutical and biomedical applications, such as polymer films, cell encapsulation, wound dressings and surgical sponges [42]. Alginate also shows minimal cytotoxic effects and reduced hemolysis when in contact with blood [16]. In early 1970s, alginate was recognised as safe to be used in food and pharmaceutical ingredients by the US Food and Drug Administration (FDA). Similar procedures have been used by Mironov et al. [43], which developed the concept of cell printing. This process prints gels, single cells and cell aggregates offering a possible solution for organ printing. Organ printing involves three main steps: pre-processing or development of "blueprints" for organs, processing or organ printing and accelerated organ maturation.

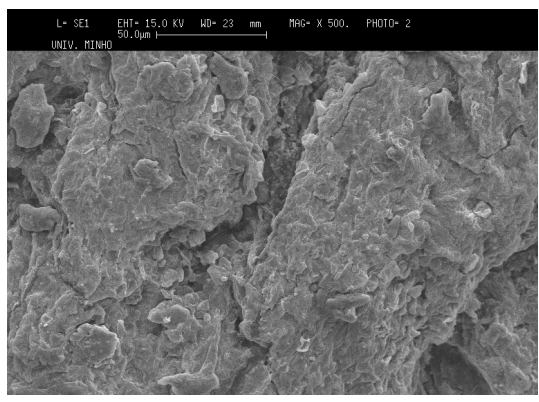

Figure 2: $\quad$ Surface morphology of an alginate solid tissue.

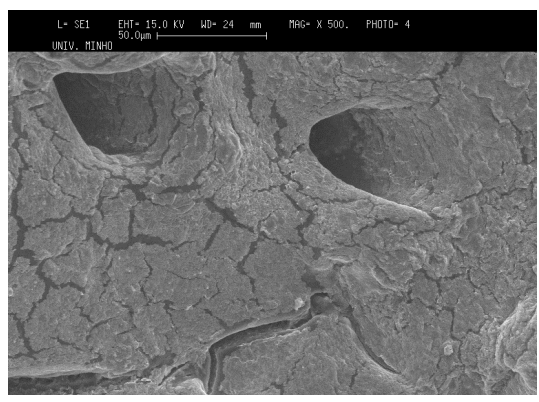

Figure 3: $\quad$ Cross section morphology of an alginate solid tissue.

Table 1 lists the main advantages and limitations of SFF for tissue engineering. Accuracy is an important issue to be addressed. Table 2 shows the main source of errors generated during the production of SFF structures for tissue engineering for each stage. 
Table 1: Characteristics of rapid prototyping scaffolds for tissue engineering.

\begin{tabular}{|c|c|c|}
\hline Rapid prototyping & Advantages & Limitations \\
\hline $\begin{array}{l}\text { Photo-polymerisation } \\
\text { processes }\end{array}$ & $\begin{array}{l}\text { Relative easy to achieve } \\
\text { small feature }\end{array}$ & $\begin{array}{l}\text { Limited by the development of } \\
\text { photo-polymerisable, } \\
\text { biocompatible and } \\
\text { biodegradable materials; low } \\
\text { geometrical complexity; } \\
\text { limited to reactive and mostly } \\
\text { toxic resins }\end{array}$ \\
\hline Laser sintering & $\begin{array}{l}\text { Relative higher scaffold } \\
\text { strength; solvent free }\end{array}$ & $\begin{array}{l}\text { Materials trapped in small } \\
\text { inner holes is difficult to be } \\
\text { removed; high temperatures in } \\
\text { the chamber }\end{array}$ \\
\hline Sheet lamination & Solvent free & $\begin{array}{l}\text { Materials trapped in small } \\
\text { inner holes is impossible to be } \\
\text { removed }\end{array}$ \\
\hline Extrusion & $\begin{array}{l}\text { No materials trapped in } \\
\text { the scaffold; solvent free }\end{array}$ & $\begin{array}{l}\text { High heat effect on raw } \\
\text { material; low geometrical } \\
\text { complexity }\end{array}$ \\
\hline Ink-jet technology & $\begin{array}{l}\text { Low heat effect on raw } \\
\text { powder; easy process; } \\
\text { low cost }\end{array}$ & $\begin{array}{l}\text { Materials trapped in small } \\
\text { inner holes; lack of } \\
\text { mechanical properties }\end{array}$ \\
\hline Bio-plotting & $\begin{array}{l}\text { Large variety } r \text { of } \\
\text { materials for both soft } \\
\text { and hard tissues }\end{array}$ & Low geometrical complexity \\
\hline
\end{tabular}

Table 2: $\quad$ Source of errors generated during the production of SFF structures.

\begin{tabular}{ll}
\hline \multicolumn{1}{c}{ Stage } & \multicolumn{1}{c}{ Source of errors } \\
\hline Digitisation & Pitch/gantry tilt \\
& Image construction algorithm \\
& Patient movements \\
& Section thickness \\
3D modeller & Threshold value \\
& Interpolation algorithm \\
& Smoothing algorithm \\
& Tesselation \\
Solid freeform fabrication & Laser or extrusion head diameter \\
& Scanning strategies \\
& Creation and removal of supporting \\
& structures \\
& Thickness of each layer \\
& Shrinkage and warping effects \\
& Surface finishing \\
\hline
\end{tabular}

\section{Conclusions}

SFF technologies have a great potential for tissue engineering. These technologies offer a high degree of freedom for tissue engineering either for the 
design of scaffolds (pore size, pore geometry, orientation, interconnectivity, etc.) or for its fabrication. Several materials can also be used enabling the production of both soft and hard scaffolds. These characteristics can enhance the fabrication of biomimetic scaffolds and scaffolds for complex biomechanical applications. Future developments will allow establishing SFF as a key tool for tissue reconstruction and regeneration.

\section{References}

[1] Chapekar, M.S., Tissue engineering: challenges and opportunities, $J$. Biomed. Mater. Res., 53, pp. 617-620, 2000.

[2] Mendes, A., Lagoa, R. and Bartolo, P.J., Rapid prototyping system for tissue engineering, Proceedings of the International Conference on Advanced Research in Virtual and Physical Prototyping, pp. 419-426, 2003.

[3] United Network for Organ Sharing website: http://www.unos.org, 2005.

[4] Lavik, E. and Langer, R., Tissue engineering: current state and perspectives, Appl. Microbiol. Biotechnol., 65, pp. 1-8, 2004.

[5] Langer, R. and Vacanti, J.P., Tissue Engineering, Science, 260, pp. 92092, 1993.

[6] Anseth, K.S. and Burdick, J.A., New directions in photopolymerizable biomaterials, Mat Res Soc Bull, 27, pp. 130-136, 2002.

[7] Nguyen, K. and West, J.L., Photopolymerizable hydrogels for tissue engineering applications, Biomaterials, 23, pp. 4307-4314, 2002.

[8] Kim, T.H., Browne, F., Upton, J., Vacanti, J.P. and Vacanti, C.A., Enhanced induction of engineered bone with basic FGF, Tissue Eng, 3, pp. 303-308, 1997.

[9] Ho, M.-H, Kuo, P.-Y, Hsieh, H.-J., Hsien, T.-Y., Hou, L.-T., Lai, J.-Y. and Wang, D.-M., Preparation of porous scaffolds by using freezeextraction and freeze-gelation methods, Biomaterials, 25, pp. 129-138, 2004.

[10] Sachlos, E. and Czernuszka, J.T., Making tissue engineering scaffolds work. Review on the application of solid freeform fabrication technology to the production of tissue engineering scaffolds, European Cells and Materials, 5 pp. 29-40, 2003.

[11] Hutmacher, D.W., Scaffold design and fabrication technologies for engineering tissues - state of the art and future perspectives, J. Biomat Sci-Polym E, 12, pp. 107-124, 2001.

[12] Gomes, M.E. and Reis, R.L., Biodegradable polymers and composites in biomedical applications: from catgut to tissue engineering. Part2 Systems for temporary replacement and advanced tissue regeneration, Int. Mat. Reviews, 40, pp.274-285, 2004.

[13] Freyman, T.M., Yannas, I.V. and Gibson, L.J., Cellular materials as porous scaffolds for tissue engineering”, Prog. In Mat. Sci., 46, pp. 273282, 2001.

[14] Velocity2 Plus software from Javelin: www.javelin3d.com (accessed April 2005). 
[15] BioBuild from Anatomics: www.anatomics.net (accessed April 2005).

[16] MIMICS from Materialise: www.materialise.com (accessed April 2005).

[17] Meurer, M.I., Nobre, L.F.S., Meurer, E., Silva, J.V.L., Bárbara, A.S., Oliveira, M.G., Silva, D.N. and Santos, A.M.B., A critical review on acquisition and manipulation of CT images of the maxillofacial area for rapid prototyping, in Advanced Research in Virtual and Rapid Prototyping, Edited by Bártolo et al, Balkema, Leiden, 2005 (to appear).

[18] Sakas, G., Trends in medical imaging: from $2 \mathrm{D}$ to $3 \mathrm{D}$, Computers \& Graphics, 26, pp. 577-587, 2002.

[19] Endo, M., Recent Progress in Medical Imaging Technology, Systems and Computers in Japan, 36, pp. 1-17, 2005.

[20] Huang, Q.H., Zheng, Y.P., Lu, M.H. and Chi, Z.R., Development of a portable 3D ultrasound imaging system for musculoskeletal tissues, Ultrasonics, 43, pp. 153-163, 2005.

[21] Levy, R.A., Chu, T.G.M., Holloran, J.W., Feinberg, S.E. and Hollister, S., CT-generated porous hydroxyapatite orbital floor prosthesis as a prototype bioimplant, Am J Neuroradiol, 18, pp. 1522-1525, 1997.

[22] Griffith, M.L. and Halloran, J.W., Freeform fabrication of ceramics via stereolithography, J. Am Ceram Soc, 79, pp. 2601-2608, 1996.

[23] Matsuda, T. and Mizutani, M., Liquid acrylate-endcapped poly $(\varepsilon-$ caprolactone-co-trimethylene carbonate). II. Computer-aided stereolithographic microarchitectural surface photoconstructs, $J$ Biomed Mater Res, 62, pp. 395-403, 2002.

[24] Rapid micro product development (RMPD) from microTEC: www.microtec-d.com (accessed May 2005).

[25] Williams, J.M., Adewunmi, A., Schek, R.M., Flanagan, C.L., Krebsbach, P.H., Feinberg, S.E., Hollister, S.J. and Das, S., Bone tissue engineering using polycaprolactone scaffolds fabricated via selective laser sintering, Biomaterials, 26, pp. 4817-4827, 2005.

[26] Lee, G. and Barlow, J.W., Selective laser sintering of bioceramic materials for implants, Proceedings of the '96 SFF Symposium, Austin, TX, August 12-14, 1996.

[27] Wang, F., Shor, L., Darling, A., Khalil, S., Güçeri, S. and Lau, A., Precision deposition and characterization of cellular poly- $\varepsilon$-caprolactone tissue scaffolds, Rapid Prototyping Journal, 10, pp. 42-49, 2004.

[28] Hutmacher, D.W., Schantz, T., Zein, I., Ng, K.W., Teoh, S.H. and Tan, K.C., Mechanical properties and cell cultural response of polycaprolactone scaffolds designed and fabricated via fused deposition modelling, J Biomed Mater Res, 55, pp. 203-216, 2001.

[29] Zein, I., Hutmacher, D.W., Tan, K.C. and Teoh, S.H., Fused deposition modeling of novel scaffolds architectures for tissue engineering applications, Biomaterials, 23, pp. 1169-1185, 2002.

[30] Woodfield, T.B.F., Malda, J., de Wijn, J., Péters, F., Riesle, J. and van Blitterswijk, C.A., Design of porous scaffolds for cartilage tissue engineering using a three-dimensional fiber-deposition technique, Biomaterials, 25, pp. 4149-4161, 2004. 
[31] Chen, Z., Li, D., Lu, B., Tang, Y., Sun, M. And Wang, Z., Fabrication of artificial bioactive bone using rapid prototyping, Rapid Prototyping Journal, 10, pp. 327-333, 2004.

[32] Widmer, M.S., Gupta, P.K., Lu, L., Meszlenyi, R.K., Evans, G.R.D., Brandt, K., Savel, T., Gurlek, A., Patrick, C.W. and Mikos, A.G., Manufacture of porous biodegradable polymer conduits by an extrusion process for guided tissue regeneration, Biomaterials, 19, pp. 1945-1955, 1998.

[33] Kim, S.S., Utsunomiya, H., Koski, J.A., Wu, B.M., Cima, M.J., Sohn, J., Mukai, K., Griffith, L.G. and Vacanti, J.P., Survival and function of hepatocytes o a novel three-dimensional synthetic biodegradable polymer scaffolds with an intrinsic network of channels, Ann Surg, 228, pp. 8-13, 1998.

[34] Zeltinger, J., Sheerwood, J.K., Graham, D.M., Mueller, R. and Griffith, L.G., Effects of pore size and void fraction on cellular adhesion, proliferation, and matrix deposition, Tissue Eng, 7, pp. 557-572, 2001.

[35] Lam, C.X.F., Mo, X.M., Teoh, S.H. and Hutmacher, D.W., Scaffold development using 3D printing with a starch-based polymer, Mater Sci. Eng., 20, pp. 49-56, 2002.

[36] Sachlos, E., Reis, N., Ainsley, C., Derby, B. and Czernuszka, J.T., Novel collagen scaffolds with predefined internal morphology made by solid freeform fabrication, Biomaterials, 24, pp. 1487-1497, 2003.

[37] Taboas, J.M., Maddox, R.D., Krebsbach, P.H. and Hollister, S.J., Indirect solid free form fabrication of local and global porous biomimetic and composite 3D polymer-ceramic scaffolds, Biomaterials, 24 pp. 181-194, 2003.

[38] Limpanuphap, S. and Derby, B., Manufacture of biomaterials by a novel printing process, Journal of Materials Science: Materials in Medicine, 13, pp. 1163-1166, 2002.

[39] Park, A., Wu, B. and Griffith, L.G., Integration of surface modification and $3 \mathrm{D}$ fabrication techniques to prepare patterned poly(L-lactide) substrates allowing regionally selective cell adhesion, J Biomater SciPolym E, 9, pp. 89-110, 1998.

[40] Pfister, A., Landers, R., Laib, A., Hübner, U., Schmelzeisen, R. and Mülhaupt, Biofunctional rapid prototyping for tissue-engineering applications: 3D bioplotting versus 3D printing, Journal of Applied Polymer Science : Part A : Polymer Chemistry, 42, pp. 624-638, 2004.

[41] Ang, T.H., Sultana, F.S.A., Hutmacher, D.W., Wong, Y.S., Fuh, J.Y.H., Mo, X.M., Loh, H.T., Burdet, E. and Teoh, S.H., Fabrication of 3D chitosan-hydroxyapatite scaffolds using a robotic dispersing system, Mater Sci Eng, C20, pp. 35-42, 2002.

[42] Bártolo, P.J., Mendes, A. and Jardini, A., Bio-prototyping, in Design and Nature II, Edited by M.W. Collins and C.A. Brebbia, WIT Press, Southampton, pp. 535-544, 2005.

[43] Mironov, V., Boland, T., Trusk, T., Forgacs, G. and Markwald, R.R., Organ printing: computer-aided jet-based 3D tissue engineering, Trends in Biotechnology, 21, pp. 157-161, 2003. 